\title{
Uma poética de dispositivos artísticos com aparatos computacionais
}

\author{
A poetic of artistic dispositives with \\ computational apparatus \\ Una poética de dispositivos artísticos con \\ aparatos computacionales
}

\author{
Leonardo Silva Souza \\ Instituição: Universidade Federal do Sul da Bahia \\ E-mail:quilombo@gmail.com \\ ORCID: https://orcid.org/0000-0002-8002-1498
}

RESUMO:

Este artigo trata de experimentos artísticos com aparatos computacionais, apresentando a ideia de uma poética de heterogêneses. Nesse âmbito, propomos o entendimento de modos de composição que lidam com materiais e formas de pensamento que são tratados de formas distintas pelos campos da arte e da tecnologia. O texto correlaciona estudos de cunho tecnológico, como os de Kowalski (1970), Robinson (2008) e Fuller (2008), aos de reflexões contemporâneas sobre arte, como os de Bishop (2012), Broeckmann (1997), Deleuze (1992; 2005), Duguet (1988) e Goffey (2009) e, a partir dessa correlação, desloca conceitos como aparelho, aparato, algoritmo, composição e dispositivo, reorientando-os a fim de erguer as bases de uma poética que se coloca entre arte e tecnologia.

Palavras-chave: Algoritmo. Dispositivo. Arte e Tecnologia.

\section{ABSTRACT:}

This paper presents the poetic of heterogenesis, dealing with artistic experiments with computational apparatus. Heterogenesis is dealt with as a mode of creative thinking from originated from compositions with different materials treated by art, science and technology. The text correlates technological studies - Kowalski (1970), Robinson (2008), Fuller (2008) - with contemporary philosophical, social and aesthetic writings - Bishop

SOUZA, Leonardo Silva. Uma poética de dispositivos artísticos com aparatos computacionais. PÓS:Revista do Programa de Pós-graduação em Artes da EBA/UFMG. v.10, n.20: nov.2020 Disponível em < https://doi.org/10.35699/2237-5864.2020.20713/> 
(2012), Broeckmann (1997), Deleuze (1992; 2005), Duguet (1988), Goffey (2009) - and displaces concepts such as apparatus, algorithm, composition, and dispositive, but directs them to rise a poetic that stands between art, science, and technology.

Keywords: Algorithm. Dispositive. Art and Technology.

\section{RESUMEN:}

Este artículo presenta la poética de la heterogénesis, abordando experimentos artísticos con aparatos computacionales. La heterogénesis se aborda como un modo de pensamiento creativo que se origina a partir de composiciones con diferentes materiales tratados por el arte, la ciencia y la tecnología. El texto correlaciona los estudios tecnológicos - Kowalski (1970), Robinson (2008), Fuller (2008) - con los escritos filosóficos, sociales y estéticos contemporáneos - Bishop (2012), Broeckmann (1997), Deleuze (1992; 2005), Duguet (1988). ), Goffey (2009) - y correlaciona conceptos como aparato, algoritmo, composición y dispositivo, pero dirigiéndolos para que surja una poética que se interpone entre el arte, la ciencia y la tecnología.

Palabras clave: Algoritmo. Dispositivo. Arte y Técnica. 


\section{Introdução}

Nos meados de 2006, Sean Cubitt, então editor-chefe da revista Leonardo, escrevia no prefácio da obra Software Studies:

As artes, ciência e a tecnologia estão experienciando um período de profunda mudança. Desafios explosivos para as instituições e práticas das engenharias, criação artística e pesquisa científica fazem surgir questões urgentes para a Ética, a produção manual, e o cuidado com o meio ambiente e seus habitantes. Modos de conhecimento e formas de beleza sem precedentes são agora possíveis, mas também surgem riscos e ameaças não esperadas. Uma nova forma de conectividade global cria novas arenas para a interação entre ciência, arte e tecnologia, mas também cria precondições para crises globais. (CUBITT apud FULLER, 2008, ix, tradução nossa, grifo nosso)

Passados treze anos, hoje, as discussões sobre o híbrido arte e tecnologia extrapolam seus domínios de origem e, sinergicamente, influenciam e se deixam influenciar pelas mais diversas áreas do conhecimento. No território da arte, há estudos que buscam referências nas ciências exatas, na ciência política, na inteligência artificial, nas neurociências e em vários outros campos. As tecnologias da computação, que incontestavelmente têm sido apropriadas por todos os territórios do conhecimento, vêm sendo constantemente revistas sob o prisma das mais diversas pesquisas, tais como as da bioinformática, dos algoritmos genéticos, das tecnologias de informação e comunicação, da educação à distância, dos webdocumentários, da segurança digital, da vida artificial, do hackerativismo e outros infindáveis exemplos. Fato indiscutível é que, enquanto este texto é lido, inimagináveis apropriações da computação estão sendo feitas rumo a novos campos de conhecimento.

Como ressaltou Cubbit, na primeira década dos anos 2000, assim como as potencialidades advindas da apropriação das tecnologias computacionais mais diversas, estavam também presentes as pré-condições para crises globais. Como os dilemas éticos de armas algorítmicas, soldados robôs, ataques hackers, manipulação de votos através de redes sociais, e objetos autônomos demonstraram, as mediações técnicas entre a computação e os diversos campos do saber não tratavam somente de utilizações de seu ferramental algorítmico, mas da insurgência de reflexões oriundas do atrelamento entre tecnologias, ciência, cultura, economia e política.

SOUZA, Leonardo Silva. Uma poética de dispositivos artísticos com aparatos computacionais. PÓS:Revista do Programa de Pós-graduação em Artes da EBA/UFMG. v.10, n.20: nov.2020 Disponível em < https://doi.org/10.35699/2237-5864.2020.20713/> 
$\mathrm{Na}$ direção de atrelar a experimentação artística com a reflexão estética, este texto trata especificamente da experimentação em arte com aparatos computacionais, apresentando discussões que potencialmente contribuam para posteriores experimentações e reflexões. Buscamos, então, apresentar uma poética de experimentação que se dá através de composições estéticas com as diferenças e particularidades entre arte e tecnologia.

Inicialmente, buscamos investigar a caracterização de uma gênese a partir de diferenças, uma heterogênese que lida simultaneamente com a experimentação artística e tecnológica. Trabalhamos com a definição de Deleuze e Guattari (2005), que tratam da heterogênese como uma forma de criação a partir da composição de diferentes materiais e formas de pensamento.

Apesar da proximidade dos termos ars e techne, por onde pode-se argumentar a descendência artística da tecnologia, entendemos que esse termo - tecnologia - pode referir-se inicialmente tanto a funções lógicas e seus encadeamentos, quanto aos aparatos técnicos e seus acoplamentos. Mas, como apresentaremos com Deleuze e Guattari (2005), há um entendimento sobre esse termo que parte de um pensamento técnico e lógico, seguindo até o pensamento heterogêneo, relacional e estético. Esta relativização, pontuada aqui pelo paralelo entre os termos aparelho e aparato, é fundamental para nossa discussão que envolve arte e tecnologia.

Noção central desta publicação, a heterogênese guarda o potencial de uma gênese própria para o atrelamento entre arte e tecnologia. Andrew Goffey, autor do texto Algorithm, no livro Software Studies (2009), realiza um detalhado estudo sobre o assunto. Ele argumenta que, na obra de Deleuze e Guattari, com esse tipo de gênese, ocorre pela primeira vez um exercício de estilo poético que envolve o pensamento científico e artístico. Encontramos em Fuller (2003) a indicação de que há um trabalho especulativo próprio do Software, o qual sugere diversas aplicações estéticas provenientes da experimentação de conexões heterogêneas entre os mais distintos campos associados a tecnologias computacionais. A estética da heterogênese, formulada primeiro por Andreas Broeckmann, ganha, na publicação desse autor, força teórica para o tratamento da experimentação com arte e tecnologia. Broeckmann, em Towards an Aesthetics of Heterogenesis (1997), junto com Goffey, em Heterogenesis and the problems of Metaphysics (2003), correlacionam Deleuze, Guattari e Foucault, apontando algumas direções para a caracterização da heterogênese como proposta poética.

SOUZA, Leonardo Silva. Uma poética de dispositivos artísticos com aparatos computacionais. PÓS:Revista do Programa de Pós-graduação em Artes da EBA/UFMG. v.10, n.20: nov.2020 Disponível em < https://doi.org/10.35699/2237-5864.2020.20713/> 
Contando com as particularidades dos campos da arte e da tecnologia, tratamos sobre como a arte pode contribuir para os entrelaçamentos entre elas. Nesse sentido, a heterogênese pode gerar intercâmbios entre os três domínios, ocorrendo quando as diferenças particulares oriundas destas áreas, as potencialidades de associação poética, são postas em sinergia, por meio de estratégias de composição. Para tratar desses intercâmbios, observamos as condições em que um dispositivo, composto por elementos heterogêneos daquelas áreas, pode ser orientado para experimentações artísticas. A partir dessas observações, pontuamos sobre como uma obra artística que envolve aparatos computacionais pode ser tratada como um dispositivo, o qual, com sua estratégia de heterogeneização e composição, pode ser voltado para a experimentação envolvendo elementos de arte e tecnologia.

Assim, caracterizamos a poética de heterogênese, a qual guarda modos de composições estéticas com aparatos computacionais - e também os não computacionais -, trazendo à tona, por meio dessas composições, os imbricamentos entre arte e tecnologia. Este trabalho apresenta, então, as noções correlatas à referida poética, caracterizando em que medida ela surge como uma composição com materiais diversos, tratados por mediação computacional.

Não se trata, portanto, de verificar as técnicas computacionais como ferramentas para a criação artística, mas, ao contrário, trata-se de erigir modos de sentir particulares da união entre arte e tecnologia, e, sobretudo, trata-se de como esses modos de sentir surgem de um tipo específico de experimentação simultaneamente artístico, científico e tecnológico. Quais são os termos da experiência estética que envolvem o sentir com as máquinas, o sentir as máquinas ou o sentir-máquina? Uma poética das coisas programadas, todavia com coisas não programáveis? Uma forma de pensamento e arte, uma abordagem de programação de dispositivos, a qual envolve amplamente os campos da ciência, da técnica e da lógica e que, com eles, cria uma gênese poética.

\section{Dispositivos, aparelhos e aparatos}

O entendimento da experimentação estética com aparatos computacionais, enquanto um possível dispositivo artístico, considera o campo de conhecimento da tecnologia na sua relação com estratégias de experimentação artística. Apesar de Foucault não citar diretamente os domínios arte ou tecnologia para apresentar o termo dispositivo, sua demarcação inicial para ele é ampla o sufici-

SOUZA, Leonardo Silva. Uma poética de dispositivos artísticos com aparatos computacionais. PÓS:Revista do Programa de Pós-graduação em Artes da EBA/UFMG. v.10, n.20: nov.2020 Disponível em < https://doi.org/10.35699/2237-5864.2020.20713/> 
ente para abordarmos as potencialidades de composição com estes dois domínios. Nesse sentido, e, ao contrário de tentar definir os atrelamentos entre arte e tecnologia pelas características essenciais dessas áreas, buscamos, com a ampla discussão demarcada pela noção de dispositivo em Foucault e Deleuze, potencializar um pensamento artístico através da heterogênese ligada a estes domínios. Então, contando com a demarcação inicial para a noção de dispositivo, buscamos abordar as diferenças entre os domínios tecnológico, científico e artístico como potência para a composição artística com aparatos tecnológicos.

O termo dispositivo é particularmente importante para nosso estudo sobre as composições artísticas envolvendo arte e tecnologia, uma vez que essa noção possibilita abarcar as estratégias de composição que estão simultaneamente relacionadas a esses domínios. Para desenvolvermos uma abordagem para dispositivos artísticos, a partir das composições que envolvem a heterogeneidade oriunda de arte e tecnologia, consideramos que nas obras Microfísica do poder (1979) e em As Palavras e as Coisas (2000), de Michel Foucault, há discussões importantes de serem levantadas concernentes à noção de dispositivo. Nosso ponto de vista sobre esse termo tem como referência principal a obra de Michel Foucault (1979; 2000), mas também a realizada por Deleuze (1989) acerca daquele autor em O que é um Dispositivo? (1989), e de textos correlatos, como o Dispositifs (1988), de Anne-Marie Duguet. É importante ressaltar ainda que Foucault não tratou do termo dispositivo artístico, mas, apesar disso, para nós, a elaboração desse termo guarda estreita relação com um pensamento artístico em um conjunto heterogêneo, que envolve materiais e aparatos diversos, tal como os computacionais, compostos em relação a múltiplas sensações nas experiências com o público.

Nessa perspectiva, um dispositivo é composto, entre outras coisas, por linhas de enunciação e linhas de subjetivação, remetendo às instâncias do poder, do saber e do sentir. As linhas de enunciação são os meios pelos quais um dispositivo emprega poder, mas o dispositivo artístico que buscamos caracterizar produz heterogêneses entre o saber e o poder através da subjetivação, o sentir. Esse processo não é estável, ao contrário, ele é, por natureza, um processo de produção de instabilidades na instância do saber e do poder.

A partir dessa demarcação inicial, o termo dispositivo assume importantes recursos para a descrição de experimentações artísticas com aparatos computacionais. São eles:

SOUZA, Leonardo Silva. Uma poética de dispositivos artísticos com aparatos computacionais. PÓS:Revista do Programa de Pós-graduação em Artes da EBA/UFMG. v.10, n.20: nov.2020 Disponível em < https://doi.org/10.35699/2237-5864.2020.20713/> 
1. um dispositivo artístico é produzido por estratégias de composição com as diferenças, linhas de subjetivação, partindo, por exemplo, do intercâmbio de comportamentos entre materiais envolvidos nas experimentações;

2. a produção de multiplicidade sobre os materiais provém de um potencial sinérgico que é tão mais marcante, quanto mais díspares são os materiais envolvidos na composição de um dispositivo.

Porém, para que seu entendimento se dê de forma consistente, é fundamental a apresentação de discussões que diferenciem os materiais envolvidos nas estratégias de composição. Apesar dessa noção de obra como dispositivo artístico, há uma camada funcional (KOWALSKI, 1979) para lidar com os aparelhos computacionais, a qual, embora seja importante delinear inicialmente, buscaremos transgredir. Para designar tal camada, comumente são utilizadas categorias epistemológicas homogeneizadoras, nas quais são classificadas peças, algoritmos, softwares e hardwares por semeIhanças em sua constituição, separando delas as potencialidades de conexões não funcionais. $\mathrm{Na}$ nossa perspectiva, consideramos um grande equívoco utilizar tais categorias para compreender a experimentação estética com aparatos computacionais. Entendemos, então, que, para detalhar a experimentação artística com aparatos computacionais, é necessário um conceito que permita a união entre a composição de sensações, característica da arte, e a produção de devires por meio dos aparatos e aparelhos. Essa união se mostra viável por meio da noção de obra como dispositivo, e heterogênese como processo de criação, pois, como exposto, os dispositivos podem propiciar linhas de subjetivação sobre os aparatos tecnológicos que os integram. Enfim, o agregado de aparelhos nunca encerraria o sentido de uma obra de arte e tecnologia e, por isso, consideramos que um dispositivo artístico é a melhor referência para abarcar o conjunto complexo que engloba a experimentação, nas suas múltiplas experiências com o público e seus aparatos e, nele, fundamos nossa perspectiva sobre o locus onde se dão as composições, as heterogêneses.

Para iniciar essa diferenciação, temos que contrapor a noção de aparato àquela designada pelo termo aparelho. Não raramente, aparelho é tratado como um conjunto cujos componentes se acoplam em torno de um propósito: seu funcionamento. Nessa direção, a expressão aparelhos computacionais designaria claramente hardware ou software, agregados ou não, acoplados ou não,

SOUZA, Leonardo Silva. Uma poética de dispositivos artísticos com aparatos computacionais. PÓS:Revista do Programa de Pós-graduação em Artes da EBA/UFMG. v.10, n.20: nov.2020 Disponível em < https://doi.org/10.35699/2237-5864.2020.20713/> 
em torno do propósito de cumprir sua função técnica. Porém, o aparato experimental a que nos referimos não é um conjunto de elementos cujo único propósito - aquilo que une - é da ordem da funcionalidade.

Nossa noção de dispositivo artístico cria heterogêneses com os enunciados lógicos e técnicos provenientes da instância do saber científico, sendo voltada para a produção de subjetividades, criando comportamentos próprios das experimentações, as quais, por sua vez, produzem sensações heterogêneas. Sobre esse posicionamento, Deleuze pontua que um pensamento a partir do dispositivo tem um certo "repúdio aos universais" (DELEUZE, 1989, p. 4). Entendemos que um dispositivo artístico não se baseia nas semelhanças e nem mesmo somente nas diferenças, mas na produção de disparidades fundamentais, de comportamentos de si. Essa é a característica estratégica com a qual agregam-se elementos nesse tipo de dispositivo: uma rede de heterogeneidades que potencialmente cria subjetivações.

Ainda que especifiquemos o dispositivo ao delimitar o campo que circunscreve os elementos envolvidos - um dispositivo computacional, um dispositivo social, um dispositivo artístico -, só há sentido ao abordar elementos em um mesmo dispositivo, na medida em que é preservada a característica do todo, a potência atrelada na junção das diferenças. Afinal, obras artísticas consideradas como dispositivos jamais se referem a agregados homogêneos de materiais de uma determinada área, ou mesmo a modos constantes de composição; ao contrário, só podemos tratar de dispositivos artísticos na medida em que podem abranger "enunciados contraditórios" (DELEUZE, 1989, p. 5), de fora de seus próprios domínios e, por isso mesmo, heterogêneos. Esses enunciados contraditórios refletem as linhas de subjetivação de forma que, "em cada dispositivo, as linhas transpõem alguns limiares, em função dos quais são estéticas, científicas, políticas, etc." (DELEUZE, 1989, p. 2). Assim, um dispositivo artístico define-se pelo modo como ele transpõe os limiares dos domínios com que lida, criando subjetividades para aquilo que o compõe.

Há, então, uma tensão intrínseca na experimentação artística quando considerada como um dispositivo: a composição com o fugidio, com o vir a ser dos materiais, com comportamentos que estão na incessante luta entre o reconhecimento de semelhanças e a imaginação das diferenças. Mas, como experimentações que buscam intervir em conjuntos de forças já constituídos, "por toda parte, há misturas a serem desfeitas: as produções de subjetividade escapam dos poderes e dos

SOUZA, Leonardo Silva. Uma poética de dispositivos artísticos com aparatos computacionais. PÓS:Revista do Programa de Pós-graduação em Artes da EBA/UFMG. v.10, n.20: nov.2020 Disponível em < https://doi.org/10.35699/2237-5864.2020.20713/> 
saberes de um dispositivo para se reinvestirem nos poderes e saberes de um outro dispositivo, sob outras formas ainda por nascer" (DELEUZE, 1989, p. 3). Duguet completa esse pensamento afirmando que tais obras "evocam contexto e referência, elas atuam através dos hibridismos múltiplos e dos confrontos que transbordam largamente os limites territoriais de cada arte para questionar os limites da arte mesma" (DUGUET, 1988, p. 222). Um dispositivo artístico com aparato computacional trata-se, então, de um tipo de dispositivo de transgressão.

Seguindo a diferenciação dos termos envolvidos na criação do dispositivo aqui tratado, temos que a expressão aparelho remete fortemente aos componentes, partes integrantes, como peças inertes. Uma caixa de som, quando tratada como output técnico, em nada influencia a Unidade Central de Processamento - C.P.U. - e seu computador na sua totalidade, e também não se deixa contaminar pela ausência de um dos demais componentes de output. Uma montagem de aparelhos computacionais é composta por peças, objetos, partes que cumprem um propósito, mas que, na sua totalidade, em nada se deixam influenciar. Nessa perspectiva, o aparelho é funcional, seu propósito é a orientação de suas partes para o bom funcionamento. Seguindo ainda essa concepção, a "máquina" pode ser também tratada como um tipo de aparelho quando considerada somente sob seu aspecto de funcionalidade, ou seja, quando vista sob a ótica de que a totalidade, a máquina, é uma entidade que tem partes orientadas unicamente para cumprir uma função predeterminada. Destarte, o aparelho, de acordo com o exposto, é unidimensional, atendendo somente a sua funcionalidade. Não nos interessa a perspectiva de que o aparelho é um conjunto de componentes funcionais, mas, ao contrário, assumimos a visada de que tais componentes sempre exercem alguma força extra-funcional, tensionando o conjunto que compõem. Então, estamos nos referindo a um tipo de aparato que se diferencia do aparelho em duas fundamentais direções:

1. o propósito do aparato que buscamos não é da ordem da funcionalidade, nos moldes que argumenta Kowalski acerca da lógica e controle funcional, mas sim, de produção de multiplicidades, heterogeneidades que não se limitam nem à lógica, nem ao desejo de controle;

SOUZA, Leonardo Silva. Uma poética de dispositivos artísticos com aparatos computacionais. PÓS:Revista do Programa de Pós-graduação em Artes da EBA/UFMG. v.10, n.20: nov.2020

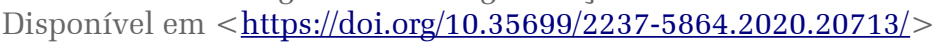


2. os elementos do aparato que buscamos não são peças, componentes, partes de um mesmo tipo, mas, ao contrário, buscamos o agregado de elementos de domínios distintos, materiais e imateriais. $\mathrm{E}$, nesse caso, podemos considerar um aparato que agrega ideias, discursos, normas, contextos e também peças, hardware e software em um mesmo conjunto.

O termo aparato tem ampla utilização sob a perspectiva da mídia arte, da estética maquinal e das poéticas tecnológicas. Broeckmann afirma a relevância desse termo em relação à experimentação com domínios diversos, pontuando que:

Uma questão fundamental para a análise da Mídia Arte continua a ser o significado atribuído ao dispositivo tecnológico, uma questão que emerge referindo-se ao uso de linguagens de programação em obras de instalação artística que exigem computadores poderosos, mas que ainda mantêm uma atitude crítica e reflexiva em relação ao potencial ideológico ou epistemológico da tecnologia. Esses contextos formularam um apelo ao estabelecimento e preservação de novos campos de experimentação, discurso e crítica, que visam o início e a revisão de processos ousados que podem retroalimentar diversos campos do saber. As transdisciplinaridades que emergem, as zonas híbridas entre teoria e prática, campos performativos etc., sempre foram projetos apoiados por aparatos. (BROECKMANN, 1997, p. 51-52)

Nesse trecho, Broeckmann aponta uma relação entre dispositivos tecnológicos e aparatos. A linha que esse autor adota traça um caminho para nossa investigação sobre uma poética de composições com materiais heterogêneos, tais como os aparatos computacionais. Ele destaca a importância de uma abordagem crítica e reflexiva na heterogênese com novas tecnologias e arte, sendo uma de nossas principais referências para a discussão que envolve dispositivos artísticos com aparatos computacionais. Para esse autor, o conceito de máquina que atende à abordagem de aparato que estamos buscando também se diferencia da perspectiva funcional do aparelho. Ele pontua que "máquinas podem também ser entendidas de outra forma, mais conceitual, como aparatos que agregam e transformam forças" (BROECKMANN, 1997, p. 55). Tal abordagem para o emprego do termo máquina é apresentada de forma que:

Não é o uso de tecnologias, por exemplo de um computador de última geração, que faz com que as experimentações levantem questões éticas e socialmente problemáticas. [...] O potencial conceitual e crítico que as novas tecnologias podem desencadear não devem ser embasados nas teorias separatistas (estéticas e éticas), mas deve permitir que se desdobrem abordagens ousadas e originadas de todos os que atuam no campo, seja como teóricos, artistas ou críticos. (KNOWBOTIC RESEARCH apud BROECKMANN, 1997, p. 51-52)

SOUZA, Leonardo Silva. Uma poética de dispositivos artísticos com aparatos computacionais. PÓS:Revista do Programa de Pós-graduação em Artes da EBA/UFMG. v.10, n.20: nov.2020 Disponível em < https://doi.org/10.35699/2237-5864.2020.20713/> 
Essa perspectiva de Broeckmann é particularmente interessante, pois busca ampliação conceitual do termo máquina, fazendo-o transcender a noção dos aparelhos envolvidos, ocupando outros domínios, apontando em direção a diversos campos do saber. Ele pontua ainda sua crítica a uma estética da funcionalidade dos aparelhos, ressaltando o papel importante do complexo heterogêneo que consideramos ser o aparato. Ele afirma que:

\begin{abstract}
Uma estética da funcionalidade tecnológica e sua implantação em contextos artísticos não é nem aceitável eticamente nem politicamente. Este tipo de crítica foi amplamente rejeitado como insuficiente e improdutivo. É importante questionar a prática artística em relação à forma como ela lida com o poder social e político agregado aos aparelhos que usa. Nesse sentido, o aparato deve de fato ser entendido como agregados de poder, como conjuntos complexos de corpos - hardware, ciclos de produção, redes, humanos, etc. - que, juntos, formam máquinas maiores, produtivas e poderosas. (BROECKMANN, 1997, p. 51-52)
\end{abstract}

Opondo-se ao destaque às técnicas de agenciamentos independentes, como na valorização excessiva de inteligência artificial ou de agentes computacionais autônomos, Broeckmann coloca ainda sua rejeição a essa perspectiva, ressaltando a concepção de máquina com a qual concordamos:

A estética do maquínico, que atualmente toma forma, não é baseada na estética das qualidades de mais ou menos agenciamento independente das máquinas, entendido como hardware técnico. Máquinas podem também ser entendidas de outra forma, mais conceitual, como aparatos que agregam e transformam forças. (BROECKMANN, 1997, p. 55)

Portanto, junto ao deslocamento conceitual que vai de aparelho a aparato, não se trata de verificar a capacidade tecnológica de mais ou menos agenciamento independente como quer a estética da funcionalidade. Entretanto, por uma via alternativa, Broeckmann destaca que:

lidar com o maquínico, nesse sentido, confronta sua ambivalência e trabalha no sentido de tornar visível sua territorialidade, dispersando e transformando-a. De fato, talvez seja possível que somente com a questão das forças de poder possamos tratar produtivamente com tais formações maquínicas. Foi Foucault quem conseguiu realizar a descrição das forças de poder como uma potência construtiva, demonstrando como a subjetivação não é o oposto, mas um produto, dos dispositivos de poder. (BROECKMANN, 1997, p. 56)

O ponto crucial que diferencia o aparelho utilizado em uma estética da funcionalidade e o aparato em uma experimentação crítica é que, nesta última, as próprias estruturas, os territórios, integram o conjunto da experimentação. Então, os aparatos que tratamos são uma estrutura repleta de

SOUZA, Leonardo Silva. Uma poética de dispositivos artísticos com aparatos computacionais. PÓS:Revista do Programa de Pós-graduação em Artes da EBA/UFMG. v.10, n.20: nov.2020 Disponível em < https://doi.org/10.35699/2237-5864.2020.20713/> 
elementos heterogêneos e voltados para uma estratégia artística, são aparatos experimentais, componentes dispostos de uma ou outra maneira, abertos à experimentação, voltados à experiência estética, não só integrantes mas imigrantes em um dispositivo.

Então, na estética do maquínico, o aparato é um conjunto de forças que vai além da funcionalidade dos aparelhos. Dessa forma, as máquinas envolvidas com o aparato não designam as mesmas máquinas dos aparelhos, pois não são máquinas de componentes computacionais, e sim máquinas de componentes heterogêneos, de forças múltiplas.

Estas máquinas vislumbram e transformam potencialidades e, portanto, circunscrevem os pontos [...] de heterogeneização, que podem multiplicar, ou serem reterritorializados em formas petrificadas, molares. Máquinas não são objetos mortos, e sim, têm sempre um estrato de proto-subjetividade e uma tendência em torno da teleologia e portanto, em torno da reflexividade, que as liga diretamente a processos de subjetivação, tema explorado por Guattari. Lidar com a estética do maquínico, então, significa sair do nível da fascinação pelo hardware técnico e entrar no nível dos movimentos, dos processos, da dinâmica, da mudança. (BROECKMANN, 1997, p. 55-56)

Assim, de acordo com Broeckmann, para tratar de aparatos com propósitos experimentais que potencialmente podem ser artísticos, a estética maquinal, ou a estética do maquínico, assume os múltiplos domínios relacionados ao maquínico, e não somente sua orientação funcional, aliando elementos heterogêneos à experimentação artística tais como os computacionais, os estéticos e os políticos.

Em síntese, temos que, para nosso tratamento da experimentação artística com materiais computacionais e não computacionais, consideramos que aparato, entendido como um conjunto heterogêneo, de propósitos múltiplos e simultâneos, é o conceito que possibilita deslocar a composição desde a estética da funcionalidade até a estética maquinal. Nessa perspectiva, nossas observações fazem constantes referências ao conceito de máquina enquanto um "agregado de poder transformador de forças" (p. 55), como indica Broeckmann (1997). E, quando nos referirmos aos objetos computacionais orientados por sua funcionalidade, os trataremos genericamente por aparelhos.

Seguindo a direção de uma estética da heterogênese proposta por Broeckmann (1997), uma vez que apresentamos o deslocamento do conceito de aparelho e aparato de seu caráter meramente funcional e técnico, consideramos que há necessidade de descrever de que forma a obra como um

SOUZA, Leonardo Silva. Uma poética de dispositivos artísticos com aparatos computacionais. PÓS:Revista do Programa de Pós-graduação em Artes da EBA/UFMG. v.10, n.20: nov.2020 Disponível em < https://doi.org/10.35699/2237-5864.2020.20713/> 
dispositivo pode articular os aparatos experimentais através das estratégias de composição e heterogeneização, tarefa que nos requer descrever as formas de criação, e outros devires, para os materiais envolvidos no dispositivo, ou seja, nos referimos aqui à criação de comportamentos programados ou montados com os aparatos tecnológicos em questão. Claro, estes não são os únicos tipos de processos e materiais heterogêneos que integram um dispositivo artístico, porém, deste tipo de material, vistos sob o domínio da computação, é possível derivar algumas relações que valerão também para outros materiais. Assim, trataremos de dispositivos artísticos como aparatos computacionais, observando como o intercâmbio de comportamentos entre os materiais envolvidos implica uma relação poética na medida em que produz sensações, oriundas dos entrelaçamentos de arte e tecnologia.

\section{O intercâmbio de comportamentos entre materiais}

Os aparatos computacionais, quando envolvidos na experimentação artística, podem ter comportamentos intercambiados com outros objetos. Por exemplo, se uma tinta é misturada ao grafite, ela passa a ser uma tinta condutora de eletricidade, com a qual a pintura de circuitos pode ser feita. Outro exemplo: se um pequeno motor giratório é posto estrategicamente dentro de uma esfera, esse dispositivo ganha características próprias provenientes da transferência do comportamento do motor à esfera, fazendo-a deslocar-se sem qualquer impulso externo. São os comportamentos heterogêneos intercambiados entre os materiais que, originalmente, os mantinham.

A produção de comportamentos heterogêneos em um dispositivo está diretamente associada com a estratégia de composição e heterogeneização do mesmo. As estratégias de composição e heterogeneização buscam produzir diferenças no próprio dispositivo, fazendo com que ele se diferencie dele mesmo, produzindo momentos de si, comportamentos. Uma forma de produzir essas diferenças em si é intercambiar comportamentos entre materiais distintos, fazendo com que o dispositivo passe a se comportar em um devir constante. Mas, há também como criar comportamentos para alguns materiais, tais como os computacionais.

O desenvolvimento de comportamentos em aparatos computacionais passa, então, a ter um papel importante na criação das estratégias de composição e heterogeneização. Através da programação de ações, ou de acoplamento físico entre aparelhos, os aparatos computacionais podem produzir

SOUZA, Leonardo Silva. Uma poética de dispositivos artísticos com aparatos computacionais. PÓS:Revista do Programa de Pós-graduação em Artes da EBA/UFMG. v.10, n.20: nov.2020

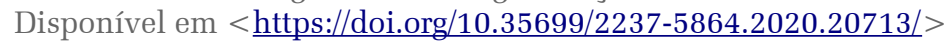


comportamentos que, por sua vez, podem ser transferidos a outros materiais não computacionais, gerando comportamentos próprios do dispositivo, ou da obra, que os engloba. Apesar de serem comportamentos programados, ou montados, as ações associadas aos materiais, que serão transferidos a outros, tornam-se geradoras de diferenças características, disparidades fundamentais, que transcendem a própria programação dessas ações e da camada funcional dos aparelhos. Uma vez que um comportamento de um material qualquer está sempre circunscrito a um determinado domínio, tal como comportamentos programados estão relacionados ao domínio funcional da tecnologia, ou um comportamento físico de um determinado material é tratado sob a ótica da física ou da química, há, no intercâmbio desses comportamentos, uma experimentação que possibilita heterogêneses entre artes e tecnologias. Assim, ainda que programados, esses comportamentos não são únicos dos aparelhos computacionais, mas sim, são devires que surgem a partir dos aparatos computacionais em associação a outros materiais não computacionais, fazendo emergir daí a forma de heterogênese tratada neste texto.

Buscando observar como uma heterogênese pode se dar através do intercâmbio de comportamentos em um dispositivo artístico, em primeiro lugar, levantamos a pergunta pelas diferenças entre os comportamentos dos aparatos experimentais e aqueles dos aparelhos computacionais. Para lidar com essa diferenciação, caracterizamos uma abordagem comportamental para os apareIhos computacionais em que os comportamentos são considerados enquanto um modo de agir e em resposta a um estímulo externo ou interno.

Consideramos, ainda, duas características:

1. Há também comportamentos não-computacionais inerentes aos objetos. Como exemplo, uma mola tem comportamentos, digamos, impulsionadores, atrativos, refratários, que respondem ao estímulo de forças externas a ela.

2. Os algoritmos e o acoplamento de hardware podem gerar determinados comportamentos para objetos. Por exemplo, um imã tem o comportamento de atrair ou afastar outros objetos metálicos, mas pode, junto à mola, ganhar o comportamento de criar carga elétrica o que, junto a dois resistores, pode produzir o comportamento de uma tomada de decisão eletrônica.

SOUZA, Leonardo Silva. Uma poética de dispositivos artísticos com aparatos computacionais. PÓS:Revista do Programa de Pós-graduação em Artes da EBA/UFMG. v.10, n.20: nov.2020

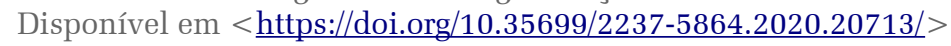


Isso posto, surge uma pergunta fundamental em relação aos dispositivos artísticos que buscamos caracterizar: em que medida os diversos materiais em uma composição, não somente os aparelhos computacionais, podem intercambiar comportamentos entre si? Em um escopo mais amplo que esta publicação, detalhamos de que forma com a abordagem comportamental os modos de agir dos aparelhos e dos demais materiais podem ser observados nos seus comportamentos atrelados, sejam eles provenientes de uma programação, do acoplamento de hardware ou da própria configuração de materiais componentes de uma obra artística. Mas, indicamos adiante algumas possibilidades.

No caso dos aparelhos computacionais, os comportamentos podem ser escritos. $\mathrm{O}$ ato de programar um aparelho cria um comportamento e um código para ele. $\mathrm{O}$ aparelho passa a agir de acordo com o código escrito e essa escrita não determina o comportamento como um todo, mas um campo de possibilidades de ações dos aparelhos. Entendemos que o código de programação implica em uma forma de escrita, no registro da programação, mas não na programação em si. Ora, quando um circuito executa o batimento de um motor, de acordo com o estímulo de um sensor do batimento cardíaco, há outros estímulos - por exemplo, o dos movimentos do corpo -, que também acionam, apesar daquilo que foi programado, o comportamento do motor. Então, embora o comportamento possa ser escrito, ele excede as possibilidades registradas no código.

No comportamento programado dos aparelhos computacionais, há ainda uma associação entre código e comportamento, entre o domínio da linguagem e o das atuações do aparelho, trata-se, então, da relação entre verbo e a ação concreta que ele pode designar. Isso ocorre por uma via de mão dupla expressa pela pergunta: como fazer com que um aparelho computacional sopre, acaricie, pulse, respire etc... e inversamente, o que vem a ser considerada uma ação do aparelho que possa ser nomeada por cada um desses verbos? Trata-se de uma relação tal qual a que sugerem Deleuze e Guattari quando abordam as sensações em uma composição artística: "Pintamos, esculpimos, compomos, escrevemos com sensações. Pintamos, esculpimos, compomos, escrevemos sensações" (DELEUZE; GUATTARI, 2005, p. 216). Da mesma forma, considerando os comportamentos em um dispositivo artístico com aparatos computacionais, poderíamos afirmar também que não só codificamos com sensações, mas que codificamos sensações. Assim, há, na escrita do comportamento programado dos aparelhos computacionais, um modo de proceder que possibilita heterogeneizar as ações programadas, associando sensações a elas.

SOUZA, Leonardo Silva. Uma poética de dispositivos artísticos com aparatos computacionais. PÓS:Revista do Programa de Pós-graduação em Artes da EBA/UFMG. v.10, n.20: nov.2020

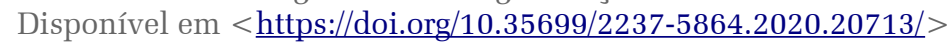


Os comportamentos podem ser criados com materiais físicos. Nesse caso, entram em jogo as forças consideradas sob as óticas da mecânica, eletromagnetismo, eletrônica e diversas outras áreas científicas. Como no caso da mola associada a um imã, o acoplamento de objetos gera comportamentos mais complexos, que em nada se assemelham aos dos objetos que os compõem nem a suas funcionalidades. No complexo mola-imã-resistor, ocorre a produção de um sinal eletrônico que pode ser processado em um circuito como indício de movimento de um botão sendo pressionado, de uma presença, ou ausência, de alguém. Mas em todos os casos, os comportamentos criados com acoplamento físico extrapolam as características de seus componentes, suas funcionalidades e seus domínios de origem. Nesse sentido, o aparelho começa a se tornar um aparato experimental, no qual comportamentos imprevisíveis podem surgir das várias experimentações de acoplamentos mais complexos envolvendo as misturas entre os domínios de origem.

Além destes dois processos, da escrita e do acoplamento físico, os comportamentos podem também ser transferidos. Tomemos, como exemplo, um motor que, quando acoplado a uma rede de outros comportamentos heterogêneos, seu acionamento ganha um nome próprio nesse dispositivo, passando a ser referenciado por este nome. Nesse momento, a codificação do comportamento associa o nome da ação a um comportamento de um material, interligando-os. Quando esse nome passa a referenciar, em abstrato, um comportamento que não mais depende da parte física do material, identifica-se uma relação entre o nome dado às ações e aquilo que ocorre, sendo esta uma segunda etapa da codificação. Quando, por último, a parte física é substituída, o motor é trocado por um ventilador, por exemplo, o comportamento é, então, transferido de um objeto a outro. Os componentes deste dispositivo criam sentido próprio devido à intencionalidade na associação dos comportamentos. A estratégia de heterogeneização está no processo de experimentação que conduz o acionamento de um motor, por exemplo, desde sua funcionalidade até o sentido próprio que cria no dispositivo. Dessa forma, a transferência de comportamentos pode se dar através de uma rede de comportamentos heterogêneos, criada não só por acoplamentos físicos mas também por sua codificação e intercâmbio.

SOUZA, Leonardo Silva. Uma poética de dispositivos artísticos com aparatos computacionais. PÓS:Revista do Programa de Pós-graduação em Artes da EBA/UFMG. v.10, n.20: nov.2020 Disponível em < $\underline{\text { https://doi.org/10.35699/2237-5864.2020.20713/> }}$ 
Nos aparelhos, os comportamentos podem advir de montagens abstratas, tornando o conjunto um aparato experimental com comportamentos heterogêneos. Ao nos referirmos aos comportamentos heterogêneos, não estamos referenciando a capacidade dos aparelhos computacionais somente, mas sim a atuação de todos os materiais em relação aos diversos domínios envolvidos no dispositivo artístico que integram.

Para fins de exemplificação, desenvolvemos um comportamento programado para gerar interferências no enunciado de Deleuze e Guattari: "Pintamos, esculpimos, compomos, escrevemos com sensações. Pintamos, esculpimos, compomos, escrevemos sensações" (DELEUZE; GUATTARI, 2005, p. 216). Esse enunciado já guarda em si um comportamento: nele, cada verbo tem uma conjugação própria e todos são posicionados estrategicamente na frase em relação à presença ou ausência da preposição com. Para demonstrarmos a criação de um comportamento programado, e com alguma pretensão estética, o comportamento desse enunciado será então assumido como premissa lógica para o algoritmo de nosso exemplo. Chamaremos essa breve experimentação de Permutação deleuziana. Nosso algoritmo (Figura 05) foi programado de forma que a estrutura de controle perca o controle, assumindo somente uma tarefa: permutar verbos na sentença original de acordo com sua conjugação, fazendo surgir outros sentidos para o enunciado de Deleuze e Guattari.

Contando com quatro estruturas de dados, sendo uma lista de verbos para cada uma das conjugações que estão dispostas na sentença original, uma sequência de ações sobre essas estruturas seleciona verbos alternativos, substituindo aqueles da frase original e verificando, a cada momento, a necessidade, ou não, da preposição com. Com os verbos escolhidos, a sentença é remontada, gerando novos sentidos baseados no comportamento original da frase de Deleuze e Guattari, mas de forma heterogênea, atribuindo sentidos pela permutação programada no algoritmo. A permutação é, então, o comportamento programado que, por sua vez, é díspar, externo, de uma outra lógica, heterogêneo ao enunciado original.

SOUZA, Leonardo Silva. Uma poética de dispositivos artísticos com aparatos computacionais. PÓS:Revista do Programa de Pós-graduação em Artes da EBA/UFMG. v.10, n.20: nov.2020 Disponível em < https://doi.org/10.35699/2237-5864.2020.20713/> 


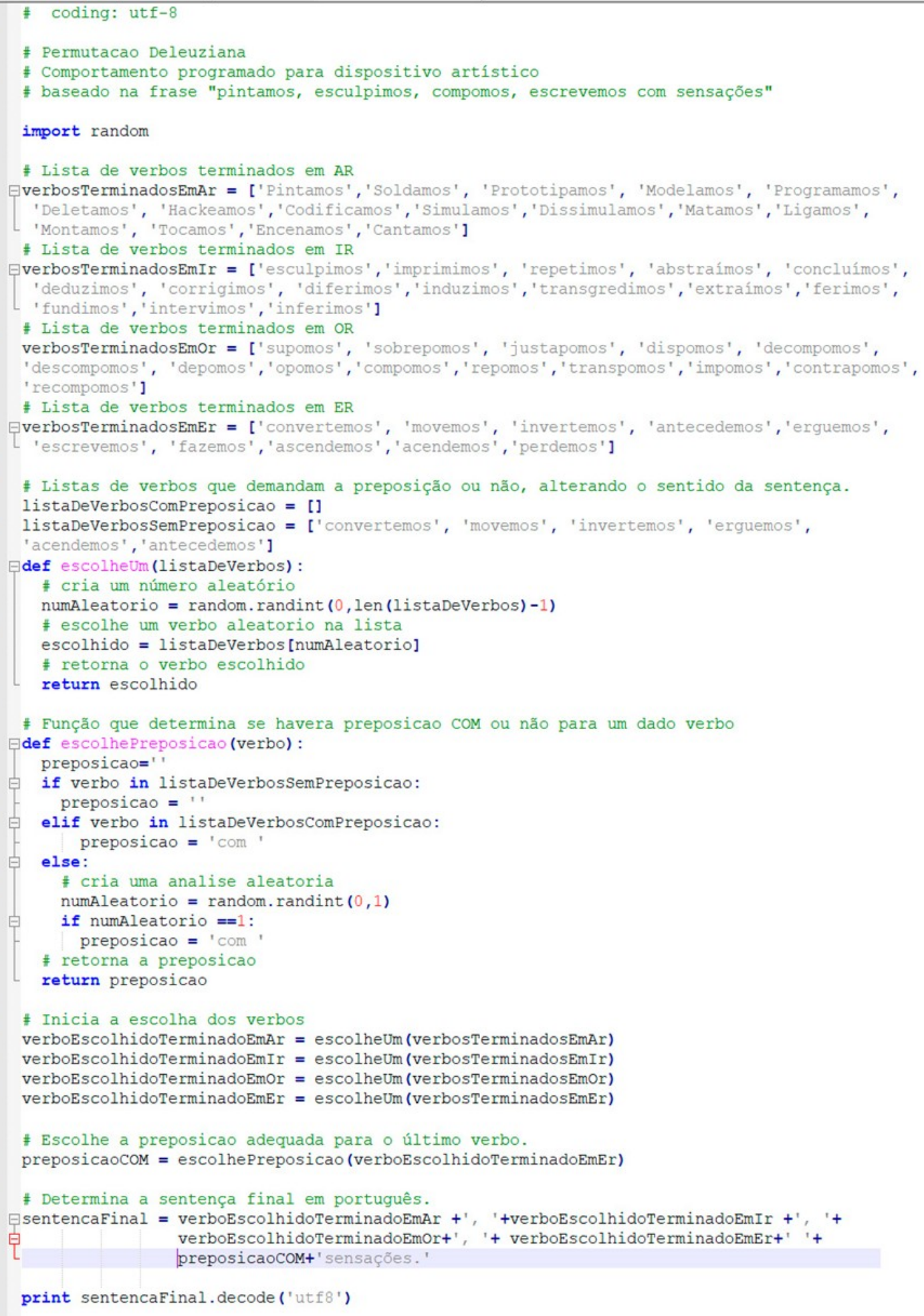

print sentencaFinal.decode ('utf8')

Fig. 1 - Permutação deleuziana - código fonte

Fonte: SOUZA, L. A poética da Heterogênese: acerca de dispositivos artísticos com aparatos computacionais. Tese de doutorado defend. no PPGArtes da EBA UFMG. 2018

SOUZA, Leonardo Silva. Uma poética de dispositivos artísticos com aparatos computacionais. PÓS:Revista do Programa de Pós-graduação em Artes da EBA/UFMG. v.10, n.20: nov.2020 Disponível em < https://doi.org/10.35699/2237-5864.2020.20713/> 
Como resultado desse algoritmo, a estrutura de controle gera ações que respondem à modelagem lógica do problema, no caso, ao posicionamento dos verbos em relação à preposição, criando outros sentidos para ela. A sequência de ações do algoritmo (Fig. 1), orientadas para a solução funcional do nosso problema, corresponde à estratégia de controle deste software. Nesse caso em específico, as estruturas de dados guardaram os verbos selecionados previamente, mas o que agregou sentido à camada lógica foi a heterogeneidade entre verbo e escolha algorítmica, associada ao comportamento da permutação.

Observando a fundo os comportamentos programados, é importante destacar que seus processos de criação estão repletos de uma forma de pensar com a heterogênese. Deleuze e Guattari explicam que o pensamento como heterogênese advém dos acoplamentos entre as formas de pensar da ciência, da filosofia e da arte. Esses autores enfatizam que, ao passo que a ciência trata de descrever os valores das variáveis por meio de funções lógicas, a arte compõe com sensações a partir das variações. Como um paralelo dessa mesma forma citada por esses autores, identificamos que, no processo de criação de comportamentos programados, foram trabalhadas tanto a descrição lógica do estado de variáveis quanto a composição de sentidos, tal como nos sentidos produzidos com os enunciados da Permutação deleuziana.

É ainda relevante perguntar pelo modo com que os aparatos computacionais possibilitam criar e intercambiar comportamentos. Nesse sentido, observamos as seguintes possibilidades:

1. De um modo analógico, entende-se: de uma mesma lógica de comportamento. Os comportamentos mantêm correlação direta entre os materiais que intercambiam comportamentos: uma trena que se ergue ou se recolhe de acordo com a proximidade de uma pessoa, um pincel que desenha a trajetória de uma pessoa em uma sala, etc.

2. De um modo digital, entende-se: de forma mediada por uma relação arbitrariamente escoIhida. Os comportamentos mantêm arbitrariamente uma associação entre os materiais e um código de output, por meio de mediação simbólica, propiciando, assim, correlações do tipo nome e coisa nomeada: a trena se ergue efusivamente em resposta a um sorriso; um pincel mecânico que propositalmente não pinta, enquanto houver alguém esperando que ele faça algo.

SOUZA, Leonardo Silva. Uma poética de dispositivos artísticos com aparatos computacionais. PÓS:Revista do Programa de Pós-graduação em Artes da EBA/UFMG. v.10, n.20: nov.2020 Disponível em < https://doi.org/10.35699/2237-5864.2020.20713/> 
Por se apresentarem como modos complementares para a criação de comportamentos, estas duas formas, analógica e digital, a contínua e a descontínua, a que se comporta tal qual analogias e uma outra, aquela que escapa à analogia, e que é proveniente de um ato de mediação simbólica, ambas são uma base para o entendimento de uma poética associada ao intercâmbio de comportamentos entre materiais heterogêneos em uma composição estética. Consideramos, então, que os aparelhos computacionais, e talvez outros materiais, possam se comportar de duas formas: uma, procedendo por analogias, imitando, em certa medida, outros comportamentos; e outra, procedendo através de comportamentos próprios, observando as características próprias do aparato, realizando codificações, mediações simbólicas, com materiais distintos. Ponto importante de nossa argumentação é que os comportamentos próprios do aparato, e não dos aparelhos, emergem do conjunto de forças próprio do dispositivo que integram e, em uma composição estética, são criadas condições para que surjam, associadas aos comportamentos próprios das obras artísticas, sensações tão heterogêneas quanto os materiais nelas envolvidos serem diferentemente tratados por arte, ciência e tecnologia.

Considerando o conjunto de nossos apontamentos, a potencialidade do intercâmbio de comportamentos está exatamente em fazer surgir outras formas de se compor com diferentes materiais nos dispositivos artísticos, e, portanto, fazer emergir sensações particulares, inerentes à composição com a diversidade de pontos de vista sobre os materiais envolvidos. Assim, a potência da estratégia de composição em um dispositivo artístico reside na busca por criar comportamentos próprios, que emergem das diferenças com que os materiais envolvidos são tratados. Este é um ponto crucial de nossa abordagem comportamental: quando os aparelhos computacionais se mesclam a outros objetos, dotando-os com comportamentos outros que não os deles mesmos, fazendo surgir outros devires de si.

\section{Uma poética de heterogêneses}

Tais questões fornecem uma abordagem para lidar diretamente com as perguntas que Claire Bishop levanta quando discute os destinos da arte digital. Ela propõe pensarmos que, enquanto vários experimentos usam tecnologia digital, é importante diferenciar aqueles que se confrontam à questão do que significa o pensar e o sentir afetados pelo digital (BISHOP, 2012, tradução nossa). Essa questão guarda uma perspectiva política na renovação dos meios de percepção pois, como

SOUZA, Leonardo Silva. Uma poética de dispositivos artísticos com aparatos computacionais. PÓS:Revista do Programa de Pós-graduação em Artes da EBA/UFMG. v.10, n.20: nov.2020 Disponível em < https://doi.org/10.35699/2237-5864.2020.20713/> 
questionam Deleuze e Guattari, "não se luta contra os clichês perceptivos e afetivos se não se luta também contra a máquina que os produz" (DELEUZE; GUATTARI, 2005, p. 195). Quando Deleuze problematiza, em Postscripts on the Societies of Control (1992), os fundamentos de uma sociedade de controle, ele descreve o enclausuramento e a disciplinarização como os meios de contenção. A estratégia de controle, referente à camada lógica do algoritmo, representa mais uma forma de moldagem do que o pensamento deve vir a ser e como ele deve vir a proceder. Ao contrário, apresentamos o pensamento como heterogênese, uma transgressão de toda forma prescrita de lidar com arte e tecnologia, uma busca incessante pelo porvir. A forma poética de composições e heterogêneses que apresentamos propõe intervir sobre uma perspectiva funcional, técnica e lógica para convocar a necessidade de uma outra, na medida em que pontua a importância de um constante devir dos materiais, ao confrontá-los com as diferenças de pensamentos dadas pelas áreas de arte e tecnologia. Com essa forma poética, apresentamos uma possibilidade de resistência ao enclausuramento lógico sobre o pensamento da tecnologia e da arte, uma forma de resistência às sociedades de controle, dissolvendo seus limiares, intercalando suas características próprias, gerando experiências simultaneamente poéticas, científicas e tecnológicas.

SOUZA, Leonardo Silva. Uma poética de dispositivos artísticos com aparatos computacionais. PÓS:Revista do Programa de Pós-graduação em Artes da EBA/UFMG. v.10, n.20: nov.2020 Disponível em < $\underline{\text { https://doi.org/10.35699/2237-5864.2020.20713/> }}$ 


\section{REFERÊNCIAS}

BROECKMANN, Andreas. Towards an Aesthetics of Heterogenesis. Convergence, v. 3, n. 2, p. 48-58, jun. 1997.

BISHOP, Claire. Digital Divide: Contemporary Art and New Media. Artforum, New York, v. 51, n. 1, sep. 2012. Disponível em: <https://www.artforum.com/print/201207/digital-divide-contemporaryart-and-new-media-31944>. Acesso em: 8 jan. 2018.

DIXON, Steve. Digital Performance: A History of New Media in Theater, Dance, Performance Art and Installation. Londres: MIT Press, 2007.

DELEUZE, Gilles; GUATTARI, Félix. Mil Platôs: capitalismo e esquizofrenia. São Paulo: Editora 34, 2008. v. 5.

DELEUZE, Gilles; GUATTARI, Félix. O que é a filosofia? São Paulo: Editora 34, 2005.

DELEUZE, Gilles. Postscript on the Societies of Control. October, Cambridge, v. 59, p. 3-7, 1992.

DELEUZE, Gilles. Qu'est-ce qu'un dispositif? In: FOUCAULT, Michel. Philosophe. Rencontre internationale, Paris 9, 10, 11 janvier 1988. Paris: Seuil, 1989.

DUGUET, Anne-Marie. Dispositifs. Communications, v. 48, Vidéo, p. 221-242, 1988. Disponível em: <http://www.persee.fr/doc/comm_0588-8018_1988_num_48_1_1728> Acesso em: 21 jan. 2018.

FOUCAULT, Michel. As palavras e as coisas: uma arqueologia das ciências humanas. Organização e tradução de Salma Tannus Muchail. São Paulo: Martins Fontes, 2000.

FOUCAULT, Michel. Microfísica do poder I. Organização e tradução de Roberto Machado. Rio de Janeiro: Edições Graal, 1979.

FULLER, Mathew. Behind the Blip: Essays on the Culture of Software. Cambridge, New York: Autonomedia, 2003.

FULLER, Mathew (Ed.). Software Studies: a lexicon. Cambridge, Massachusetts: MIT Press, 2008.

GOFFEY, Andrew. Algorithm. In: FULLER, Matthew (Ed.). Software studies: a lexicon. Cambridge, Massachusetts: MIT Press, 2008a. p. 15-20.

GOFFEY, Andrew. Intelligence. In: FULLER, Matthew (Ed.). Software studies: a lexicon. Cambridge, Massachusetts: MIT Press, 2008b. p. 132-142.

GOFFEY, Andrew. Heterogenesis and the Problems of Metaphysics. In: ROBINSON, Keith (Org.). Deleuze, Whitehead, Bergson: Rhizomatic Connections. Nova York: Palgrave Macmillan, 2009. p. 106-127.

KOWALSKI, Robert. Algorithm = Logic + Control. Communications of the ACM, London, n. 7, jul., 1979. Disponível em: <https://www.doc.ic.ac.uk/ rak/papers/algorithm\%20=\%20logic\%20+ \%20control.pdf> Acesso em: 09 out. 2017.

SOUZA, Leonardo Silva. Uma poética de dispositivos artísticos com aparatos computacionais. PÓS:Revista do Programa de Pós-graduação em Artes da EBA/UFMG. v.10, n.20: nov.2020

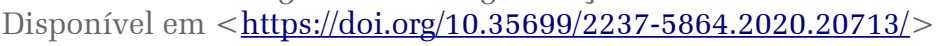


LINS, Consuelo. Rua de Mão Dupla: documentário e arte contemporânea. In: MACIEL, Kátia (Org.). Transcinemas. Rio de Janeiro: Contracapa, 2006. Disponível em: $<$ http://www.videobrasil.org.br/ffdossier/Ruademaodupla_ConsueloLins.pdf>. Acesso em: 19 jan. 2018.

NEVES, José Pinheiro. $\mathbf{O}$ apelo do objeto técnico. Porto: Campo das Letras, 2006.

ROBINSON, Derek. Analog. In: FULLER, Matthew (Ed.). Software studies: a lexicon. Cambridge, Massachusetts: MIT Press, 2008. p. 21-30.

SOUZA, Leonardo Silva. Uma poética de dispositivos artísticos com aparatos computacionais. PÓS:Revista do Programa de Pós-graduação em Artes da EBA/UFMG. v.10, n.20: nov.2020 Disponível em < https://doi.org/10.35699/2237-5864.2020.20713/> 